\title{
The Inconsistent Effects of Plain English Disclosures on Nonprofessional Investors' Risk Judgments
}

\author{
Jennifer Riley ${ }^{1, *}$ and Eileen Taylor ${ }^{2}$ ii \\ 1 College of Business Administration, University of Nebraska Omaha, Omaha, NE 68182, USA \\ 2 Poole College of Management, North Carolina State University, Raleigh, NC 27695, USA; eztaylor@ncsu.edu \\ * Correspondence: jenriley@unomaha.edu
}

Received: 19 December 2017; Accepted: 22 February 2018; Published: 2 March 2018

\begin{abstract}
In this paper, we examine whether the readability of different types of corporate risk disclosures influences the risk judgments of nonprofessional investors. Our study contributes evidence to the Security and Exchange Commission's ongoing initiative to improve corporate financial statement disclosures. Using 359 responses from an experimental survey of nonprofessional investors (NPIs), we find that readability, in conjunction with risk factor type, significantly influences investors' judgments of probability and size of economic loss, cause for worry, and overall risk. NPIs judged the risk from an industry-related risk factor (competition) to be higher when written in plain English, but judged the risk of a company-specific risk factor (internal control weakness over financial reporting) to be higher when written in a less readable format (i.e., legalese). We found no significant differences in judgments between plain English and less readable language on a combined industry/company risk factor, information security. Results suggest that a move to plain English for all types of risk factors may have consequences that are not fully understood or expected. This area needs further research before regulators enact (or enforce) mandates for risk factors to be presented in plain English.
\end{abstract}

Keywords: plain English; readability; risk factor disclosures; item 1a; nonprofessional investors

\section{Introduction}

In this paper, we report the results of an experimental study of nonprofessional investors' (NPIs) judgments of corporate risk disclosures and whether the readability of the disclosures impacts their risk judgments. In doing so, we contribute evidence to the Security and Exchange Commission's (SEC) ongoing initiative to improve corporate financial statement disclosures. Several regulatory developments are specifically relevant to our research. The first is the recent Concept Release, Business and Financial Disclosure Required by Regulation S-K, which is part of the Division of Corporate Finance's goal of improving the usefulness of disclosures for investors (SEC 2016). The Release reports on the SEC's evaluation of Regulation S-K's disclosure requirements and requests public comments on changes to the regulation (SEC 2016).

Second, and included under the SEC's evaluation of Regulation S-K, is the requirement that mandates that organizations disclose risks " ... that may adversely affect the issuer's business, operations, industry, or financial position, or its future financial performance" (SEC 2004; SEC 2005). Item 503(c) of Regulation S-K requires that these risks be provided under the heading "Risk Factors" in Section 1a of 10-K filings. Finally, related to both is the directive that these risk disclosures be written in plain English. The SEC enumerated plain English principles in Release No. 33-7497 Plain English Disclosures. Such principles include: (1) short sentences; (2) definite, concrete, everyday words; (3) active voice; (4) tables or bullet point lists; (5) no legal jargon and highly technical business terms; and (6) no multiple negatives (SEC 1998).

Taken together, these SEC actions are founded on the same primary objective of improving disclosure for the benefit of investors, and in conjunction, their desire to assist the "least-sophisticated investors" 
(SEC 1998). On its face, requiring disclosures to be complete and readable seems obvious. Benefits of similar initiatives have been shown in other areas, including financial services (Campbell 1999), insurance (Blazzard and Hasenauer 1998), and mutual funds (Johnson 2004). However, a number of studies offer conflicting results on the effectiveness and efficiency of such requirements in relation to financial reporting and disclosures, and raise concerns about the unexpected effects on NPIs. Rennekamp (2012) concludes that investors are more likely to overreact to financial information when earnings press releases are written in plain English. Tan et al. $(2014,2015)$ show that the effects of readability are not consistent, and may reverse when other variables such as language tone and benchmarks are included. Cui (2016) introduces evidence regarding the impact of investor financial sophistication, finding that it interacts with readability to influence investor processing of earnings releases. Taylor and Riley (2017) support Cui's findings in the context of risk factor disclosures specifically. In sum, the extant research raises concern about investors' abilities to use disclosures, and consequently, about regulators attempts to improve them.

In this paper we provide further evidence to this literature by examining the effect of readability for three different risk topics within Section 1a. We believe that this greater specificity contributes to the growing body of research on the style and presentation of disclosures, and the subsequent effect on users' behavior. By providing three distinct risk topics, our study focuses on the differential effects of the topic disclosed, while simultaneously investigating each for the influence of readability. Further, our study contributes to this literature because our subject pool is comprised of the members of an education and support association developed specifically for NPIs. Thus, our conclusions are based directly upon the responses of individuals who are the target of the SEC's initiatives on plain English disclosures.

Using survey responses from 359 NPIs, we investigate how readability affects judgments related to three types of risk factors. The risk factors, developed in Taylor and Riley (2017), draw on actual 10-K risk disclosures and from prior research on industry and firm-level risk disclosures (e.g., Kravet and Muslu 2013; Bao and Datta 2014). One factor addresses a general industry-level risk: the competitive environment, a second factor addresses a firm-level risk: internal controls weakness, and a third factor address a risk with implications for both industry and firm: cybersecurity over data. For two of the three, competitive environment and internal control weakness, we find that investors judge the probability and size of economic loss, worry, and overall risk differently when the risk is communicated in plain English compared with a less readable presentation. We find no significant differences for readability on the third risk factor, security. These results lead us to the tentative conclusion that plain English requirements are not a panacea, readability effects are not consistent across disclosures, and ultimately, that a focus on plain English may be diverting attention from other challenges to the SEC's goal of providing useful information to the investing public.

These results should be of interest to the SEC in their continued push to make financial reporting more usable to all investors, as well as public companies, nonprofessionals, and standard-setters. This area will benefit from additional research, and theory development and testing, to understand and predict how written language influences investment decisions.

\section{Background and Hypothesis Development}

\subsection{Improving Disclosure}

The SEC's 2016 Concept Release seeks public comment on suggested changes to disclosures required by Regulation S-K. It signals a recognition that meeting investor demand for information may be more complicated than simply expanding disclosures and mandating specific presentation. The SEC's stated objective in the Release is to determine, among other things, whether "specific disclosures are important or useful to making investment and voting decisions" and whether and how the requirements should be revised to "enhance the protection of investors" (SEC 2016, pp. 7-8). 
The Release identifies several areas of specific concern that are relevant to this paper: (1) whether and how specific line items, including risk factors, are important and useful to the decisions of investors; and (2) whether the presentation and delivery of disclosures can be improved to increase the usefulness to investors. Some of the questions asked include whether companies should be required to rank risk factors by their importance, whether emerging and firm-specific risks are being reported rather than generic risks, and whether the benefits outweigh the costs of risk disclosure (i.e., Mazor et al. 2016; Erickson and Rancher 2016).

In addition to the content, the SEC expresses concern about the presentation of disclosures. Throughout the Concept Release the SEC refers to the question of "whether current disclosure requirements should be revised to include different formats to facilitate the readability" (SEC 2016, p. 22). They go on to state: "(w)e are especially interested in feedback on how we can improve the content and readability of the risk factors included in a filing as well as the potential advantages and disadvantages of different approaches to risk-related disclosures" (SEC 2016, p. 146). In this paper, we contribute to this effort by providing experimental evidence on NPIs' judgments of Section 1a Risk Factors, and whether the topic and the readability of a risk disclosure influences these judgments.

\subsection{Risk Disclosure}

Risk has been defined as the possibility that an event will occur and adversely affect the achievement of objectives (COSO 2004). The disclosure of risk fills a vital role in the capital markets by mitigating the moral hazard in a principal (investor) agent (management) relationship. Risk reports inform investors of inside information related to management's assessment of the potential for these events to occur. Abraham and Cox (2007) discuss three types of risk disclosures: business risk, financial risk, and internal control risk. Risk disclosures enable more accurate stock valuation and reduce unrealistic performance expectations (Deumes 2008), by increasing transparency for non-insiders. Disclosure benefits both managers and investors by reducing information asymmetry, preventing stock bubbles through quicker market price corrections, and attracting capital (Hutton 2004; Deumes 2008). The provision of risk information may also protect companies from litigation and reputation costs by acting as a preemptive disclaimer (Skinner 1997, 1994). Recognizing these benefits, investors and regulators have been campaigning for greater corporate transparency on risk for several decades (Deumes 2008; Buffett 2003; Ryan 1997).

The SEC began addressing these calls in earnest in 1997 by issuing Financial Reporting Release No. 48 (FRR 48), which requires that companies disclose quantitative and qualitative information about market risk exposures from financial instruments, such as interest rate and foreign currency exposure (SEC 1997). Prior to this mandate, SEC regulations had only encouraged registrants to provide market risk disclosures. Research on FRR No. 48, however, raises concerns about the effects of risk disclosure on investor behavior. Koonce et al. (2005a) show that the information firms provide in FRR No. 48 disclosures causes systematic problems in investors' risk judgments. Their findings indicate a robust labeling effect, such that investors' judgments of risk vary according to the label given to a financial instrument. The authors argue that investors' misperceptions are contrary to economic theory, which can have serious implications for firm pricing.

Hodder et al. (2001) identify three main deficiencies in FRR No. 48 that may result in inappropriate risk assessments: the flexibility allowed in disclosure formats, insufficient requirements for quantitative information, and the absence of potential gain information. The flexibility of FRR No. 48 increases the possibility of opportunistic disclosure or management manipulation. Management may disclose every minor risk in order to obscure major ones, depict more favorable perspectives, or exclude some risks entirely (Hodder et al. 2001; Deumes 2008). The lack of quantitative information in the risk disclosures poses an additional challenge, as prior research indicates that information that must be inferred, estimated, or calculated will be used less than information that is explicitly stated or quantified (Hodder et al. 2001; Johnson et al. 1988; Anderson and Koonce 1998). Hodder et al. (2001) conclude that FRR No. 48 does not require sufficient quantitative information, and that the qualitative information 
is not compensatory. The authors note that "it is very difficult, if not impossible, for individuals to use (this) qualitative information to generate their own quantitative risk assessments" (p. 63). Last, the absence of potential gain information encourages investors to consider risk in unintended and unexpected ways for two reasons (Hodder et al. 2001; Koonce et al. 2005a). First, psychology research supports the notion that potential gains are a component of risk assessments (Luce and Weber 1986). Absent this information, investors are likely to selectively consider possible gain outcomes and perceive greater risk than is warranted (Hodder et al. 2001). Second, individuals' risk assessments are partially determined by their ability to imagine or recall instances of risk (Slovic et al. 1980). Predominant exposure to or focus on loss, as is the case in Regulation S-K disclosures, may contribute to an overestimation of risk (Hodder et al. 2001). Nelson and Rupar (2015) indicate that investors' risk judgments based on FRR No. 48 disclosures are affected by whether the disclosure is dollar-formatted or percentage-formatted.

When examining the relevance of risk factors, Abraham and Shrives (2014, p. 91) find that "company managers prefer providing disclosures that are symbolic rather than substantive." They attribute this outcome to institutional factors and proprietary costs. Institutional factors exert pressure on managers to mimic others in the same industry and to over-rely on, for lack of a better phrase, prior year's work papers. In this situation, it is less risky (and less useful to investors trying to differentiate companies from each other) to report the same risks as others in the same industry and to report the same risk from year to year. This practice necessitates reporting more general, non-specific risks (Abraham and Shrives 2014). Proprietary costs drive managers to balance the benefit of detailed and specific disclosures with the cost of publicizing information which competitors could use to harm the company. This pressure also reduces the likelihood that companies will disclose detailed, specific risks, as they seek to avoid tipping off the competition.

Evidence from the U.K. also raises questions regarding the usefulness of risk disclosures. Linsley and Shrives $(2005 a, 2005 b)$ conclude that risk narratives in the annual reports of UK companies lack coherence and do not provide a complete picture of risk. The authors find that companies disclose minimal quantitative risk information, and instead provide generalized statements of risk policies. Consequently, the authors argue, stakeholders cannot adequately determine the company's risk profile. The collective findings of this research stream are particularly relevant to our study, as they indicate that characteristics other than the information content of risk factors impact investor decisions.

Undaunted, the SEC continued on the path toward increased risk reporting in 2005 by requiring a new section in all companies' 10-Ks: Section 1a Risk Factors. This section is intended to alert investors and others to the wide range of risks involved in owning, loaning to, or doing other business with public companies. To comply with the new regulation, companies must list and discuss " ... the most significant factors that make a company speculative or risky" (SEC 2005). To the best of our knowledge, only a few published studies address risk disclosure in Section 1a specifically. Kravet and Muslu (2013) examine the full annual report for the number of risk sentences before and after Section 1a was required. They find that the increase in number of risk sentences is associated with higher return volatility, particularly negative returns. Additionally, Kravet and Muslu detect stronger reactions to industry-level risk disclosures than to firm-specific disclosures. However, because they examine the entire 10-K, the effect cannot be specifically isolated to Section 1a Risk Factors.

Campbell et al. (2014) restrict their study to Section 1a, and examine the type of risk factor more specifically. They offer evidence that supports the usefulness of this section, and conclude that the disclosures provide relevant information. Investors are sensitive to both industry-level and firm-specific risk factors. Bao and Datta (2014) stratify Section 1a disclosures into 30 types, and find that the majority (22 out of 30 ) have little association with investor decisions or market behavior. For those remaining factors with an effect, Bao and Datta find that industry-level risks increase risk judgments while firm-level risks decrease them. Taylor and Riley (2017) add to this archival research with an experimental study of Section 1a Risk Factors. They find that the readability of the risk factors influences NPIs' equity valuations and judgments of management credibility. Taken together, these 
studies' results indicate that the type and format of risk disclosed matters, although the nature of the effect is not consistent across studies.

\subsection{Plain English and Readability}

An explicit stipulation made by the SEC in S-K is that disclosures be written using plain English principles. Plain English is defined by the SEC as (1) short sentences; (2) definite, concrete, everyday words; (3) active voice; (4) tables or bullet point lists; (5) no legal jargon and highly technical business terms; and (6) no multiple negatives (SEC 1998). The SEC contends that risk factors written in plain English provide a clearer and more concise summary of the risks of investment in the issuer's stock (SEC 2004). This stipulation is in keeping with the SEC's philosophy that "all investors, whether large institutions or private individuals, should have access to certain facts about an investment" (SEC 2010).

The SEC is justified in its concern. Research shows that the complexity of financial reports has increased to the point where a NPI is unable to use them (Courtis 2004, 1998, 1995; Linsley and Lawrence 2007; Smith and Taffler 1995; Miller 2010). Despite the SEC's efforts, there has been no evidence of improvement in readability since Jones and Shoemaker (1994) labeled financial reports as "inaccessible" and demanding of an undergraduate or postgraduate degree for comprehension. In fact, Li (2008) documents that readability has declined even farther.

On its face, this should encourage even greater attention and enforcement efforts. After all, the push for plain English seems intuitively reasonable, and should help ensure a more level playing field for all investors (Elliott et al. 2007). However, the belief that plain English can achieve this goal remains an unconfirmed assumption, and a number of studies suggest that plain English communications have unintended, negative consequences (Bernstein 2006; Jacoby et al. 1982). Rennekamp (2012) finds that when press releases are more readable, small investors overreact by responding more positively to good news and more negatively to bad news, and that this result appears unintentional. Tan et al. (2014) show that other variables such as language tone may reverse the effects of readability. Cui (2016) focuses on investor characteristics, and finds that their financial literacy interacts with readability to influence judgments after earnings releases.

Most recently, Taylor and Riley (2017) extend this line of study to risk disclosures. They report that increased readability appears to compensate for lower financial sophistication of some investors, to the extent that their equity valuations are not significantly different than investors with higher sophistication. However, when readability is low, less-sophisticated investors believe management to be less competent, but more sophisticated investors believe management to be more competent. Thus, although improved readability through the use of plain English disclosures may have some positive benefits for less-financially sophisticated investors, its effects are not consistent. This is problematic because companies will not publish two versions of the 10-K, one that follows plain English principles and one that does not (which describes most 10-Ks currently). In sum, this body of research indicates a more complex relationship between investors and readability than previously assumed, one that demands continued study.

\subsection{Hypothesis}

We add to the evidence discussed above in a number of ways. First, Taylor and Riley (2017) examine the effect of readability in a group of risk factors on investors' judgments of equity and management competence. The study we describe here looks at the risk factor topics specifically and distinctly. Second, Rennekamp (2012), Tan et al. (2014), and Cui (2016) use quantitative earnings press releases to examine readability in NPIs. These reports are different from risk factor disclosures, as they can report both positive and negative information, they stand alone from other corporate reporting, they relate to earnings results, and most importantly, they contain quantitative information.

Similarly, research on FRR No. 48 is explicitly related to market risk and is generally more quantitative (e.g., Nelson and Rupar 2015). Unlike FRR No. 48, Regulation S-K directs companies to disclose any significant risk relating to the business, with no requirements for type, format (other 
than plain English), or quantitative information. The SEC included the caveat "where appropriate" in the description guiding risk factor disclosures. Doing so allows management to decide what risk factors it will disclose, and when it will disclose them. Because the SEC guidelines indicate that a company should disclose events that may "adversely affect" the company, the information provided in Section 1a risk disclosures is wholly negative and one-sided. Thus, it is broader, more subjective, and more open to manipulation than is FRR No. 48. If a fundamental problem of FRR No. 48 is too much flexibility, resulting in a lack of quantitative information and a one-sided focus (Hodder et al. 2001; Schrand and Elliott 1998), it seems logical to question the potential effects of the even greater latitude allowed in Section 1a.

Lastly, by conducting an experiment with NPIs we are able to isolate their judgments of risk to specific risk topics individually, while also capturing the effect of varying levels of readability of risk disclosures. Most of the studies on Section 1a reviewed earlier (e.g., Campbell et al. 2014; Bao and Datta 2014) were conducted on stock market returns and analysts' forecasts, in response to published 10-Ks. As a result, conclusions are drawn in the aggregate, on the market's behavior after exposure to the complete body of risk factor disclosures. Investor behavior cannot be isolated to individual risk factors, nor can it be studied for influence of readability. Since the SEC appears committed to 'leveling the playing field' it is imperative that we continue efforts to better understand how it affects decisions.

Taking all of the above research into consideration, we know that the behavior and decisions of investors are affected by more than the content of a disclosure. Characteristics that likely should be irrelevant, including presentation characteristics such as the labels, formats, and language style, can lead to misperceptions in the market. We also know that the topic covered in the risk disclosure influences decisions, which we would expect that it rightly should. However, neither the nature of this effect, nor is its interaction with the presentation characteristics, is clear or consistent. Because the prior research predicts differing reactions to the readability of disclosures, we propose the following non-directional hypothesis:

Hypothesis 1 (H1). The readability of risk disclosures will impact the risk judgments of nonprofessional investors, and this effect will differ for different risk factor topics.

\section{Method and Materials}

\subsection{Participants}

Study participants consisted of 359 NPIs who are members of BetterInvesting, Inc. This organization provides support and other educational resources for NPIs. Staff at BetterInvesting Inc., agreed to email a link to our experimental survey to their registered members. Members were guaranteed anonymity for their responses. The survey was created in an online survey software application. The only access to the survey is through the link emailed by BetterInvesting Inc., to their members, it was not publically available. We focus on NPIs because they make up an increasingly large portion of equity participants, the SEC has indicated a desire to level the playing field between professionals and nonprofessionals (Elliott et al. 2007), and prior readability research has noted the inability for NPIs to access annual report information (Jones and Shoemaker 1994).

\subsection{Design}

The experiment is a $2 \times 3$ mixed design, with random assignment of participants to either more or less readable treatments, and with all participants making judgments about three risk factors. All participants reviewed the same financial statements and background information for a fictional company. The data included three risk factors presented in varying order to control for potential order effects. The risk factors, developed in Taylor and Riley (2017), are similar to those reported in a random sample of 100 of the Fortune 500 companies. Risk factors cover three areas: competitive industry environment, information security, and internal control over financial reporting. We use these because 
we wanted to present a diverse set of factors, while avoiding information overload. We also wanted to design our experiment to capture possible differential effects related to risk factor topic.

The first risk factor described the systematic, industry-level risk resulting from a competitive environment and potentially negative effects of changing consumer preferences. The second factor describes an information security risk stemming from the possibility that proprietary data could potentially be exposed. We contend that information security has both industry and firm-level components. Although the specific security measures employed are firm-level, the high level of global interconnectivity, almost daily reports of breaches and attacks, and the growing apathy of the public toward security failures (Chemi 2014; Yayla and Hu 2011) has created a sense that every company will get hacked. Finally, the third factor addressed a firm-level risk that an internal control weakness at the organization may compromise the reliability of the financial reports.

The readability of both the less and more readable risk factors were assessed with the Flesch Reading Ease score (Flesch 1948) and the Flesch-Kincaid Grade Level Index (Kincaid et al. 1975). The Flesch Reading Ease score has been widely-used and accepted across disciplines as a reliable measure of readability (Rogers et al. 2007). Higher scores indicate more readable text. The Flesch-Kincaid Grade Level Index maps the Reading Ease score to accepted U.S. education system grade levels. See the Appendix A for the full text of the risk factors.

\subsection{Task}

After reviewing the information, participants provided their judgments of each risk factor for the following dependent variables: probability of economic loss, size of economic loss, cause for worry, and overall risk from the specific risk factor. The survey instrument was developed from validated instruments from prior literature. Koonce et al. (2005b) provide the source of our survey questions and dependent variables. They draw upon decision-theory variables (Libby and Fishburn 1977; Lipe 1998) and Slovic's (1987) behavioral variables to jointly address how individuals judge risk. Our survey questions are drawn from their validated instrument. Following Koonce et al. (2005b), we assess the validity of our instrument by altering the order of risk factors and reversing the scale on several questions. The results presented in the following section were not influenced by the presentation order. Finally, we asked several questions to assess the validity of our language manipulation. Differences between the two groups are significant in the expected direction for the following two questions: the risk factors were easy to read ( $t=-5.04, p<0.01$, two-tailed) and were written in plain English $(t=-5.21, p<0.01$, two-tailed). Accordingly, we conclude that our manipulation was successful. We collected standard demographic data, including age, investing experience, and education level.

\section{Results}

The email distribution of the instrument resulted in 359 responses, collected during the time period of 2011-2012. The sample of respondents includes 58\% males and $42 \%$ females. Participants averaged age 65.03 years with 23.38 years investing experience, and took an average of 25 min to complete the survey. Complete demographic data is presented in Table 1.

Table 1. Demographic Data.

\begin{tabular}{ccc}
\hline Measure & $\boldsymbol{n}$ & Mean (SD), Range \\
\hline Number of years investing & 358 & $23.38(13.09), 0-62$ years \\
Average \# of trades per year & 359 & $10.23(14.25), 0-120$ trades \\
Average age & 359 & $65.03(10.06), 23-90$ years \\
\hline \multicolumn{2}{c}{ Gender = 58\% Male $(207 / 359) ; 42 \%$ Female $(152 / 359)$} \\
\hline Highest Degree Earned & Frequency & Percent $(\%)$ \\
\hline
\end{tabular}


Table 1. Cont.

\begin{tabular}{ccc}
\hline Measure & $\boldsymbol{n}$ & Mean (SD), Range \\
\hline High School & 5 & 1.4 \\
Some College/ Associate's Degree & 42 & 11.7 \\
Bachelor's Degree & 141 & 39.3 \\
Graduate Degree & 171 & 47.6 \\
Total & 359 & 100 \\
\hline Field of Highest Degree & Frequency & Percent $(\%)$ \\
Accounting \& Finance & 36 & 10.0 \\
Other Business & 67 & 17.8 \\
Health Care & 50 & 13.9 \\
Engineering & 39 & 10.9 \\
Education & 36 & 10.0 \\
Physical Sciences & 31 & 8.6 \\
Other College Degree & 98 & 27.3 \\
High School Diploma & 5 & 1.5 \\
Total & 359 & 100 \\
\hline
\end{tabular}

We conduct a series of mixed ANOVAs to assess NPIs' responses on the dependent variables. The between-subjects factor is comprised of two independent groups: more readable (plain English) disclosures and less readable disclosures. The within-subjects factor has three related groups: risk factor topic 1 (RF1-competitive environment), 2 (RF2-security), and 3 (RF3-internal control). As presented in Table 2, there are statistically significant interactions between the readability treatment and risk factor topics on all dependent variables: probability of economic loss, $F=20.89, p<0.001$; magnitude of economic loss, $F=11.99, p<0.001$; cause for worry, $F=25.80, p<0.001$; and overall risk $F=19.69$, $p<0.001$. These results support our Hypothesis, suggesting that individuals respond differently to each risk topic, and its readability, as they read and process the information provided in the organization's risk factor disclosure section.

Table 2. Mixed ANOVAs of Readability (between subjects) and Risk Factors (within subjects).

\begin{tabular}{|c|c|c|c|c|}
\hline & df & Mean Square & $F$ & $p$-Value * \\
\hline \multicolumn{5}{|c|}{ Dependent Variable $(D V)$ : Probability of economic loss $(0=$ zero probability to $10=$ certainty $)$} \\
\hline Readability $\times$ Risk factors & 2 & 74.50 & 20.89 & $<0.001$ \\
\hline Error & 714 & 3.57 & & \\
\hline \multicolumn{5}{|c|}{ DV: Magnitude of economic loss ( $0=$ zero loss to $10=$ large loss $)$} \\
\hline Readability $\times$ Risk factors & 2 & 43.80 & 11.99 & $<0.001$ \\
\hline Error & 714 & 3.65 & & \\
\hline \multicolumn{5}{|c|}{ DV: Cause for worry $(0=$ no worry to $10=$ high worry $)$} \\
\hline Readability $\times$ Risk factors & 2 & 83.52 & 25.80 & $<0.001$ \\
\hline Error & 714 & 3.24 & & \\
\hline \multicolumn{5}{|c|}{$D V:$ Overall risk $(0=$ no risk to $10=$ high risk $)$} \\
\hline Readability $\times$ Risk factors & 2 & 56.97 & 19.68 & $<0.001$ \\
\hline Error & 714 & 2.90 & & \\
\hline
\end{tabular}

Because the interactions are significant, we next perform simple main effects testing by examining differences in risk responses between treatment groups (readability) at each category of the within-subject factor (risk factors). The results are presented in Table 3. On all dependent variables, there was a statistically significant difference in risk responses between treatment groups for RF1-competition and RF3-internal controls. Compared to the low readability condition, those with plain English disclosures indicated significantly greater probability of economic loss from RF1 
$(F=11.72, p<0.01)$; greater magnitude of economic loss $(F=10.79, p<0.01)$; greater cause for worry $(F=5.44, p=0.02)$; and greater overall risk $(F=4.74, p=0.03)$. The results we found for RF1 were flipped for RF3. Compared to the low readability condition, those with plain English disclosures indicated significantly lower probability of economic loss from RF3 ( $F=14.05, p<0.01)$; lower magnitude of economic loss $(F=5.26, p=0.02)$; lower cause of worry $(F=21.39, p<0.01)$; and lower overall risk $(F=17.40, p<0.01)$. In sum, this indicates that NPIs judged the risk from RF1-competitive environment to be higher when written in plain English than when written in less readable form. NPIs judged the risk from RF3-internal controls to be lower when written in plain English than when written in less readable form.

Table 3. Simple Main Effect Tests for Readability within each Risk Factor ${ }^{1}$.

\begin{tabular}{cccc}
\hline Dependent Variable & $\begin{array}{c}\text { RF1: Competitive } \\
\text { Environment }\end{array}$ & $\begin{array}{c}\text { RF2: Information } \\
\text { Security }\end{array}$ & $\begin{array}{c}\text { RF3: Internal } \\
\text { Control Weakness }\end{array}$ \\
\cline { 2 - 4 } & $\begin{array}{c}\boldsymbol{F} \\
\text {-Value }\end{array}$ & $\begin{array}{c}\boldsymbol{F} \\
p \text {-Value }\end{array}$ & $\begin{array}{c}\boldsymbol{F} \\
\boldsymbol{y} \text {-Value * }\end{array}$ \\
\hline Probability of economic loss & 11.72 & 0.58 & 14.05 \\
$(0=$ zero probability to $10=$ certainty $)$ & $p<0.01$ & $p<0.45$ & $p<0.01$ \\
\hline Magnitude of economic loss & 10.79 & 0.00 & 5.26 \\
$(0=$ zero loss to $10=$ large loss $)$ & $p<0.01$ & $p<0.98$ & $p<0.02$ \\
\hline Cause for worry & 5.44 & 1.97 & 21.39 \\
$(0=$ no worry to $10=$ high worry $)$ & $p<0.02$ & $p<0.16$ & $p<0.01$ \\
\hline Overall risk to the firm & 4.74 & 0.30 & 17.40 \\
$(0=$ no risk to $10=$ high risk $)$ & $p=0.03$ & $p<0.86$ & $p<0.01$ \\
\hline
\end{tabular}

* All $p$-values are two-tailed. ${ }^{1}$ This table presents the results of differences in risk responses between treatment groups (readability) at each category of the within-subject factor (risk factors).

Unlike both of these risk factors, there were no significant differences for RF2-security on any of the four dependent variables. Responses were not impacted by more readable versus less readable disclosures for the probability of economic loss $(F=0.58, p=0.45)$; magnitude of economic loss $(F=0.00$, $p=0.98)$; cause of worry $(F=1.97, p=0.16)$; and overall risk $(F=0.30, p=0.86)$. Security is the only one of the three risk factors we provided where readability did not have any significant impact on participants' risk responses.

We are cautious in comparing the three risk factors within each readability condition. We did not make normative predictions, nor do we suggest that any one of the risk factors should be judged to be riskier than either of the others, regardless of its readability. However, what is interesting in reviewing the responses is the differences in relative overall riskiness of the three topics, as determined by the means. Descriptive statistics including mean and standard deviations for the four dependent variables for each of the three risk factors are reported in Table 4. Looking only at the low readability condition, RF1-competitive environment is judged as the least risky of the factors and RF3-internal control is judged as the most risky. In the high readability condition only, RF3-internal control is judged as the least risky and RF1-competitive environment is judged as the most risky of the factors. Figure 1 graphically presents the pattern of effect for an average of all DVs noted in Table 4. The pattern is consistent across all four outcomes (probability and magnitude of economic loss, cause for worry, and overall risk to the firm). The implications of these findings are not completely clear, as again, we do not propose a normative expectation of risk. But, they do suggest that readability impacts the perceived riskiness of risk topics differently, and that more study is needed to determine how the presentation of risk factors influences NPI's decisions. These findings are meaningful when viewed in the context of the broader literature on readability and in the SEC's continued pursuit of plain English initiatives. 
Table 4. Means (Standard Deviations) by Dependent Variable and Risk Factor.

\begin{tabular}{ccccccc}
\hline & \multicolumn{2}{c}{$\begin{array}{c}\text { RF1: Competitive } \\
\text { Environment }\end{array}$} & \multicolumn{2}{c}{$\begin{array}{c}\text { RF2: Information } \\
\text { Security }\end{array}$} & \multicolumn{2}{c}{$\begin{array}{c}\text { RF3: Internal Control } \\
\text { Weakness }\end{array}$} \\
\cline { 2 - 7 } & \multicolumn{2}{c}{ Leadability (Low $n=169 ;$ High $n=190)$} \\
\hline Dependent Variable: & High & Low & High & Low & High \\
\hline $\begin{array}{c}\text { Probability of economic loss } \\
(0=\text { zero probability to 10 = certainty) }\end{array}$ & $5.89(2.16)$ & $6.71(2.31)$ & $6.27(2.56)$ & $6.11(2.64)$ & $6.32(2.66)$ & $5.26(2.44)$ \\
\hline $\begin{array}{c}\text { Magnitude of economic loss } \\
(0=\text { zero loss to 10 = large loss })\end{array}$ & $6.17(2.32)$ & $6.95(2.19)$ & $7.52(2.29)$ & $7.53(2.47)$ & $7.09(2.58)$ & $6.48(2.51)$ \\
\hline $\begin{array}{c}\text { Cause for worry } \\
(0=\text { no worry to 10 = high worry) }\end{array}$ & $5.51(2.47)$ & $6.14(2.57)$ & $6.14(2.48)$ & $5.77(2.55)$ & $6.43(2.78)$ & $5.12(2.58)$ \\
\hline $\begin{array}{c}\text { Overall risk to the firm } \\
(0=\text { no risk to 10 = high risk })\end{array}$ & $6.17(2.02)$ & $6.66(2.15)$ & $6.47(2.21)$ & $6.52(2.41)$ & $6.56(2.52)$ & $5.50(2.33)$ \\
\hline Average of all DVs: & $6.17(2.02)$ & $6.65(2.15)$ & $6.47(2.21)$ & $6.52(2.41)$ & $6.56(2.52)$ & $5.49(2.33)$ \\
\hline
\end{tabular}

\begin{tabular}{|l|l|l|l|}
\hline & & & \\
\hline & 5.00 & & \\
\hline \\
\hline
\end{tabular}

Figure 1. Average of all DVs.

\section{Discussion}

In this study, we hypothesize that NPIs' risk assessments differ when different types of risk topic disclosures are presented in plain English compared to when presented in less readable language. Research indicates that financial reports have become too complex for NPIs to read and understand (Miller 2010). The SEC, which has stated its intention of leveling the playing field for NPIs, has responded by requiring that risk disclosures in the $10-\mathrm{K}$ be written using plain English principles. Some research suggests that few appear to be following this requirement (Blaskovich et al. 2012), which raises questions about the SEC's enforcement of its own regulations. A bigger issue, however, is whether the requirement itself is beneficial. A growing number of studies cast doubt on the seemingly common-sense initiative (e.g., Jacoby et al. 1982; Bernstein 2006; Rennekamp 2012; Tan et al. 2014). The objective of our study is to provide experimental evidence on this issue.

The significant interactions between readability and risk topics on all four measures of risk judgments indicate that readability does influence NPIs' judgments. Subsequent tests of simple effects reveal that the effect of readability is not consistent across risk factors. In other words, plain English does not uniformly change risk judgments in the same direction. Risk may be judged higher 
when written in plain English (risk from the competitive environment), lower (risk from internal controls weakness), or the same (risk from information security) than when written in less readable form. This presents a troubling implication for companies and investors. Recognizing the potential, a company may choose to selectively obfuscate risks that pertain to an industry-wide issue, such as the competitive environment, thereby encouraging a lower evaluation of risk from investors. At the same time, the company may use plain English for a firm-specific risk, such as an internal control weakness, again encouraging a lower evaluation of risk. The Incomplete Revelation Hypothesis proposes that management may obfuscate information in order to hide bad news (Bloomfield 2002). Although evidence on the prevalence of this is mixed (e.g., Linsley and Lawrence 2007; Courtis 2004), our results suggest that companies could influence risk assessments through selective readability if they so choose. When companies recognize the potential to affect risk by selectively using plain English, they could artificially manipulate investors' risk assessments. Investors will be forced to expend greater resources to identify selective readability and then attempt to 'back out' its effects. This is assuming that investors can be made aware of the potential effects of selective readability, and develop the ability to recognize and reverse it.

Because we did not make normative predictions about how the riskiness of each factor should be perceived, we do not know whether NPIs' judgments were improved by or suffered from plain English. What we do know is that risk judgments are different, confirming prior research conclusions that investors are influenced by characteristics other than the content of the disclosures. Further, we know that investors' risk judgments are affected by disclosure readability, but not consistently across disclosures. The effect is dependent on the type or topic of disclosure. Future research may build on this finding to develop a more detailed taxonomy of readability effects on various disclosure topics.

For regulators, the question becomes whether the concern over presentation style of financial reports is focused on the right target. The SEC has pushed for plain English reporting to provide a more level playing field for some time. Our study adds to prior research that raises issue with the somewhat rote acceptance of the benefits of plain English (e.g., Jacoby et al. 1982; Bernstein 2006; Rennekamp 2012; Tan et al. 2014). At present, there appears little evidence to clearly support the plain English initiatives. More research is needed to understand whether increased readability is beneficial to the investor and the market. Some have questions whether the SEC should expend resources on investors who do not possess sufficient financial knowledge to adequately analyze financial statements and disclosures regardless of readability (Anandarajan et al. 2000). The SEC itself suggests " ... it could be argued that disclosures should be tailored to those users most likely to actively follow a registrant, transact in the registrant's securities and set the market price" (SEC 2016, p. 58). Rather than increasing readability in financial reporting, it is worth considering whether the SEC's resources may be better expended on increasing financial reporting literacy in investors (Anandarajan et al. 2000). It may be the case that NPIs are able to read and understand risk disclosures regardless of readability, but that changing the language alters some other decision process. For example, Research has long recognized that decision outcomes decline when the amount of information exceeds a decision maker's processing capacity (Morunga and Bradbury 2012; Chewning and Harrell 1990). It may be that reducing the quantity of disclosures would be more effective than increasing the readability. Indeed, recent research finds that risk factor disclosure is one of the three disclosure topics (out of 150 total) that account for nearly all of the increase in the length of 10-Ks over the last 20 years (Dyer et al. 2017), The SEC may also want to consider whether this (or other types of) information can effectively be communicated in plain English. Is some information simply too complex to be adequately reported in this manner? Future research should examine this possibility. Further, regulators can use our results to guide their attempts to provide useful information and avoid unnecessary waste of resources. In sum, it presents a more pressing issue deserving greater attention. We do not intend to imply that plain English goals are wrong, but rather to support a call for more research to be undertaken before more resources are expended. 
Further, while the SEC has expanded risk reporting, research has not provided consistent support for its usefulness. Relevant risk information is company-specific and dynamic (Deumes 2008), which "does not lend itself to standardization (Hutton 2004, p. 9). Schrand and Elliott (1998) argue that risk disclosure information is not reliable because the requirements are "subjective, open-ended and ambiguous, which allows firms to report almost anything (or nothing) without violating the requirements" (p. 274). Thus, the value of risk disclosure is related to managers' choices of what information to disclose and how to disclose it. Unfortunately, the nature of risk information may preclude any attempts to institute more structure. While we did not evaluate usefulness of the risk disclosures in this paper, we mention this here because it is another aspect of disclosure reform that should be considered in concert with plain English mandates.

As is the case with all experimental research, our findings are subject to several limitations. The experimental materials are limited, and NPIs would have access to much more information about their potential investments. Also, because we did not make claims as to the accuracy of NPIs' risk assessments, future research that includes a greater number of disclosures and financial information offers the potential to further examine the effect of information overload and readability on NPIs in conjunction. Such research may be designed to specifically elicit higher or lower risk assessments, thereby examining the effect of readability on the salience of risk factors. Lastly, our respondents likely expended less effort on a hypothetical case than they would in an actual investment situation. A controlled experiment involving compensation for investment choices may increase participants' engagement. Despite these limitations, we contend that our results, obtained from a relatively large sample of active NPIs, offer important implications for regulators as well as opportunities for future research.

This paper examines the question of whether the readability of corporate risk disclosure influences NPIs' risk judgments. We use an experimental survey to gather 359 responses from NPIs, and find that readability does influence NPIs' judgments, but not consistently across risk factors. This evidence contributes to the SEC's ongoing initiative to improve corporate disclosure by suggesting that mandates for plain English language has unintended consequences. The SEC's goal of leveling the playing field for NPIs may be laudable. However, our research, in conjunction with prior research on financial report complexity and readability, suggests that this relationship may be much more complex than expected. Future research may provide better direction for furthering the goal of providing useful financial information.

\section{Patents}

This section is not mandatory, but may be added if there are patents resulting from the work reported in this manuscript.

Acknowledgments: The authors acknowledge the assistance of Better Investing Inc. for providing access to survey participants, and receipt of a 2010 AAA Steve Berlin/CITGO grant to support this research. No funds were received for covering the costs to publish in open access. We also thank two anonymous reviewers and workshop participants at NC State University, the AAA ABO Midyear meeting, and the AAA Annual meeting for the their helpful feedback.

Author Contributions: The authors, Jennifer Riley and Eileen Taylor, contributed equally to all aspects of this research. Jennifer Riley and Eileen Taylor conceived, designed, and performed the experiments, analyzed the data, and wrote the paper.

Conflicts of Interest: The authors declare no conflict of interest.

\section{Appendix A. Risk Factor Disclosures in Low versus High Readability}

\section{Appendix A.1. Risk Factor 1-Less Readable}

We must continue to differentiate our services from those of our competitors; we operate in an evolving industry that requires us to anticipate changes in client preferences and deliver services that demonstrate value to our clients. We operate in a highly competitive environment and in an industry 
that is subject to significant ongoing changes from market pressures brought about by client demands, as well as business consolidations, strategic alliances, legislative reform and marketing practices. These factors require us to differentiate our services by anticipating changes in client preferences and delivering services that demonstrate value to our clients. Failure to anticipate changes in client preferences and deliver services that demonstrate value to our clients can affect our ability to retain or grow our client base, which can adversely affect our results of operations.

Flesch Reading Ease 24.2

Flesch-Kincaid Grade Level 16.4

Appendix A.2. Risk Factor 1-More Readable (Plain English)

Our sales and profits depend on our competitors and clients' behavior. We operate in a constantly changing industry where many different events occur that might hurt our sales and profits. We need to be aware of market trends and respond quickly to our competitors and clients' behaviors. If we do not keep up with the competition, we could lose clients, sales, and profits.

Flesch Reading Ease 59.2

Flesch-Kincaid Grade Level 8.9

\section{Appendix A.3. Risk Factor 2-Less Readable}

We would be adversely affected if we fail to adequately protect client payroll and other sensitive information. We maintain large amounts of client payroll and other sensitive data about our clients in the ordinary course of our business. Our business therefore depends substantially on our clients' willingness to entrust us with their human resource related and other sensitive information. Events that negatively affect that trust, including failing to maintain appropriate safeguards to keep sensitive information secure, whether as a result of our action or inaction or that of one of our vendors, could expose us to litigation and other proceedings, fines and/or penalties, any of which could adversely affect our business, operating results or financial condition.

Flesch Reading Ease 21.6

Flesch-Kincaid Grade Level 17.5

Appendix A.4. Risk Factor 2-More Readable (Plain English)

As part of our daily operations, we receive and retain large amounts of personal information about our clients and their employees. Our clients provide this information to us because they believe we will keep it confidential. If we do not keep their information confidential, we will lose their trust and our reputation might suffer. Additionally, clients could sue us and we could be fined and assessed penalties.

Flesch Reading Ease 53.4

Flesch-Kincaid Grade Level 9.9

\section{Appendix A.5. Risk Factor 3-Less Readable}

The Company's internal controls may not be sufficient to ensure timely and reliable financial information. As reported under Item 9a of this Form 10-K, the Company's management completed its assessment of the effectiveness of the Company's internal control over financial reporting as of 31 December 2009 and based on that assessment, concluded that the Company maintained effective internal control over financial reporting as of 31 December 2009. The Company's auditor has issued an attestation report on management's assessment that expresses unqualified opinions on management's assessment and on the effectiveness of the Company's internal control over financial reporting. Still, however, the Company's growth continues to place stress on its internal controls, and there can be no assurance that the Company's control procedures will continue to be adequate. The effectiveness of the Company's controls and procedures may be limited by a variety of risks, including, among other things, faulty human judgment, simple errors, omissions and mistakes, collusion of two or more 
people or inappropriate management override of procedures. If the Company fails to have effective internal controls and procedures for financial reporting in place, it could be unable to provide timely and reliable financial information.

Flesch Reading Ease 2.6

Flesch-Kincaid Grade Level 20.9

Appendix A.6. Risk Factor 3-More Readable (Plain English)

In order to produce timely and reliable financial reports, we need effective internal controls. We completed a formal assessment of our internal control system and found it to be effective. Our auditors agree. If our existing controls weaken, we may be unable to prepare timely and reliable financial information. This could happen because of our growth, human errors and mistakes, collusion, or management override.

Flesch Reading Ease 35.2

Flesch-Kincaid Grade Level 11.5

Source: Taylor and Riley (2017)

\section{References}

Abraham, Santhosh, and Paul Cox. 2007. Analysing the determinants of narrative risk information in UK FTSE 100 annual reports. The British Accounting Review 39: 227-48. [CrossRef]

Abraham, Santhosh, and Philip J. Shrives. 2014. Improving the relevance of risk factor disclosure in corporate annual reports. The British Accounting Review 46: 91-107. [CrossRef]

Anandarajan, Asokan, Gary Kleinman, and Dan Palmon. 2000. Investors' expectations and the corporate information disclosure gap: A perspective. Research in Accounting Regulation 14: 245-60.

Anderson, Urton, and Lisa Koonce. 1998. Evaluating the sufficiency of causes in audit analytical procedures. Auditing: A Journal of Practice \& Theory 17: 1-12.

Bao, Yang, and Anindya Datta. 2014. Simultaneously discovering and quantifying risk types from textual risk disclosures. Management Science 60: 1371-91. [CrossRef]

Bernstein, David. 2006. Do investors gain from new SEC disclosure? International Financial Law Review 25: 32-34.

Blaskovich, Jennifer, Christopher J. Davis, and Eileen Z. Taylor. 2012. Enterprise risks, rewards, and regulation. Journal of Applied Business Research 28: 563-79. [CrossRef]

Blazzard, Norse N., and Judith A. Hasenauer. 1998. This is our plea for plain English. National Underwriter 102: $16-18$

Bloomfield, Robert J. 2002. The "Incomplete Revelation Hypothesis" and financial reporting. Accounting Horizons 16: 233-43. [CrossRef]

Buffett, W. 2003. Avoiding a "mega-catastrophe". Fortune, 82-87.

Campbell, N. 1999. How New Zealand consumers respond to plain English. Journal of Business Communication 36: 335-61. [CrossRef]

Campbell, John L., Hsinchun Chen, Dan S. Dhaliwal, Hsin-Min Lu, and Logan B. Steele. 2014. The information content of mandatory risk factor disclosures in corporate filings. Review of Accounting Studies 19: 396-455. [CrossRef]

Chemi, Eric. 2014. Investors Couldn't Care Less about Data Breaches. Bloomberg. Available online: https:/ /www. bloomberg.com/news/articles/2014-05-23/investors-couldnt-care-less-about-data-breaches (accessed on 16 December 2017).

Chewning, Eugene G., and Adrian M. Harrell. 1990. The effect of information load on decision makers' cue utilization levels and decision quality in a financial distress decision task. Accounting, Organizations and Society 15: 527-42. [CrossRef]

Committee of Sponsoring Organizations of the Treadway Commission (COSO). 2004. Enterprise Risk Management-An Integrated Framework. New York: COSO.

Courtis, John K. 1995. Readability of annual reports: Western versus Asian evidence. Accounting, Auditing and Accountability Journal 16: 4-17. [CrossRef] 
Courtis, John K. 1998. Annual report readability variability: Tests of the obfuscation hypothesis. Accounting, Auditing and Accountability Journal 11: 459-71. [CrossRef]

Courtis, John K. 2004. Corporate report obfuscation: Artefact or phenomenon? British Accounting Review 36: 291-312. [CrossRef]

Cui, Xiao Carol. 2016. Calisthenics with words: The effect of readability and investor sophistication on investors' performance judgment. International Journal of Financial Studies 4: 1. [CrossRef]

Deumes, Rogier. 2008. Corporate risk reporting. Journal of Business Communication 45: 120-57. [CrossRef]

Dyer, Travis, Mark Lang, and Lorien Stice-Lawrence. 2017. The evolution of 10-K textual disclosure: Evidence from Latent Dirichlet Allocation. Journal of Accounting E Economics 64: 221-45.

Elliott, W. Brooke, Frank D. Hodge, Jane Jollineau Kennedy, and Maarten Pronk. 2007. Are M.B.A. students a good proxy for nonprofessional investors? The Accounting Review 82: 139-68. [CrossRef]

Erickson, A. J., and Clint Rancher. 2016. Big Disclosure Changes Ahead? SEC Issues Concept Release Exploring Overhaul of Regulation S-K. Lexology. Available online: https:/ / www.lexology.com/library/detail.aspx?g= 4e822e82-49ed-4368-b605-8bac29edfa40 (accessed on 16 December 2017).

Flesch, Rudolph. 1948. A new readability yardstick. Journal of Applied Psychology 32: 221-33. [CrossRef] [PubMed]

Hodder, Leslie, Lisa Koonce, and Mary Lea McAnally. 2001. SEC market risk disclosures: Implications for judgment and decision making. Accounting Horizons 15: 49-70. [CrossRef]

Hutton, Amy. 2004. Beyond financial reporting: An integrated approach to disclosure. Journal of Applied Corporate Finance 16: 8-16. [CrossRef]

Jacoby, Jacob, Margaret C. Nelson, and Wayne D. Hoyer. 1982. Corrective advertising and affirmative disclosure statements: Their potential for confusing and misleading the consumer. Journal of Marketing 46: 61-72. [CrossRef]

Johnson, Don T. 2004. Has the Security and Exchange Commission's Rule 421 made mutual fund prospectuses more accessible? Journal of Financial Regulation and Compliance 12: 51-63. [CrossRef]

Johnson, Eric J., John W. Payne, and James R. Bettman. 1988. Information displays and preference reversals. Organizational Behavior and Human Decision Performance 42: 1-21. [CrossRef]

Jones, Michael John, and Paul A. Shoemaker. 1994. Accounting narratives: A review of empirical studies of content and readability. Journal of Accounting Literature 13: 142-84.

Kincaid, J. Peter, Robert P. Fishburne, Richard L. Rogers, and Brad S. Chissom. 1975. Derivation of New Readability Formulas (Automated Readability Index, Fog Count, and Flesch Reading Ease Formula) for Navy Enlisted Personnel. Research Branch Report 8-75; Orlando: Institute for Simulation and Training, University of Central Florida.

Koonce, Lisa, Marlys Gascho Lipe, and Mary Lea McAnally. 2005a. Judging the risk of financial instruments: Problems and potential remedies. The Accounting Review 80: 871-95. [CrossRef]

Koonce, Lisa, Mary Lea McAnally, and Molly Mercer. 2005b. How do investors judge the risk of financial items? The Accounting Review 80: 221-41. [CrossRef]

Kravet, Todd, and Volkan Muslu. 2013. Textual risk disclosures and investors' risk perceptions. Review of Accounting Studies 18: 1088-122. [CrossRef]

Li, Feng. 2008. Annual report readability, current earnings and earnings persistence. Journal of Accounting and Economics 4: 221-47. [CrossRef]

Libby, Robert, and Peter C. Fishburn. 1977. Behavioral models of risk taking in business decisions: A survey and evaluation. Journal of Accounting Research 15: 272-92. [CrossRef]

Linsley, Philip M., and Michael J. Lawrence. 2007. Risk reporting by the largest UK companies: Readability and lack of obfuscation. Accounting, Auditing and Accountability Journal 20: 620-27. [CrossRef]

Linsley, Philip M., and Philip J. Shrives. 2005a. Examining risk reporting in UK companies. The Journal of Risk Finance 6: 292-305. [CrossRef]

Linsley, Philip M., and Philip J. Shrives. 2005b. Transparency and the disclosure of risk information in the banking sector. Journal of Financial Regulation and Compliance 13: 205-14. [CrossRef]

Lipe, Marlys Gascho. 1998. Individual investors' risk judgments and investment decisions: The impact of accounting and market data. Accounting, Organizations and Society 23: 625-40. [CrossRef]

Luce, R. Duncan, and Elke U. Weber. 1986. An axiomatic theory of conjoint, expected risk. Journal of Mathematical Psychology 30: 188-205. [CrossRef] 
Mazor, Christine, Lisa Mitrovich, and Doug Rand. 2016. SEC Concept Release Seeks Comments on Regulation S-K. Heads-Up. Available online: https:/ / www.iasplus.com/en-us/publications/us/heads-up/2016/issue-12 (accessed on 16 December 2017).

Miller, Brian P. 2010. The effect of reporting complexity on small and large investor trading. The Accounting Review 85: 2107-43. [CrossRef]

Morunga, Maria, and Michael E. Bradbury. 2012. The impact of IFRS on annual report length. Australasian Accounting Business \& Finance Journal 6: 47-62.

Nelson, Mark W., and Kathy K. Rupar. 2015. Numerical formats within risk disclosures and the moderating effect of investors' concerns about management discretion. Accounting Review 90: 1149-68. [CrossRef]

Rennekamp, Kristina. 2012. Processing fluency and investors' reactions to disclosure readability. Journal of Accounting Research 50: 1319-54. [CrossRef]

Rogers, Richard, Kimberly S. Harrison, Daniel W. Shuman, Kenneth W. Sewell, and Lisa L. Hazelwood. 2007. An analysis of Miranda warnings and waivers: Comprehension and coverage. Law and Human Behavior 31: 177-92. [CrossRef] [PubMed]

Ryan, Stephen G. 1997. A survey of research relating accounting numbers to systematic equity risk, with implications for risk disclosure policy and future research. Accounting Horizons 11: 82-95.

Schrand, Catherine M., and John A. Elliott. 1998. Risk and financial reporting: A summary of the discussion at the 1997 AAA/FASB conference. Accounting Horizons 12: 271-82.

Securities and Exchange Commission (SEC). 1997. Disclosure of Accounting Policies for Derivative Financial Instruments, and Derivative Commodity Instruments and Disclosure of Quantitative and Qualitative Information about Market Risk Inherent in Derivative Financial Instruments, Other Financial Instruments, and Derivative Commodity Instruments; Nos. 33-7386; 34-38223; IC-22487; FR 48; International Series No. 1047; File No. 27-35-95; Washington: SEC.

Securities and Exchange Commission (SEC). 1998. A Plain English Handbook: How to Create Plain English Disclosure. SEC Office of Investor Education and Assistance. Available online: http:/ /www.sec.gov/pdf/ handbook.pdf (accessed on 16 December 2017).

Securities and Exchange Commission (SEC). 2004. Financial Reporting Release No. 33-8501. Available online: https:/ / www.sec.gov/rules/proposed/33-8501.htm (accessed on 16 December 2017).

Securities and Exchange Commission (SEC). 2005. Financial Reporting Release No. 33-8591. Available online: https: / / www.sec.gov/rules/final/33-8591.pdf (accessed on 16 December 2017).

Securities and Exchange Commission (SEC). 2010. The Investor's Advocate: How the SEC Protects Investors, Maintains Market Integrity, and Facilitates Capital Formation. Available online: http://www.sec.gov/ about/whatwedo.shtml (accessed on 16 December 2017).

Securities and Exchange Commission (SEC). 2016. Business and Financial Disclosure Required by Regulation S-K. Available online: https:/ / www.sec.gov/rules/concept/2016/33-10064.pdf (accessed on 16 December 2017).

Skinner, Douglas J. 1994. Why firms voluntarily disclose bad news. Journal of Accounting Research 32: 38-60. [CrossRef]

Skinner, Douglas J. 1997. Earnings disclosures and stockholder lawsuits. Journal of Accounting and Economics 23: 249-82. [CrossRef]

Slovic, Paul. 1987. Perception of risk. Science 236: 280-85. [CrossRef] [PubMed]

Slovic, Paul, Baruch Fischhoff, and Sarah Lichtenstein. 1980. Facts and fears: Understanding perceived risk. In Societal Risk Assessment: How Safe Is Safe Enough? Edited by Schwing, Richard C. and Walter A. Albers. San Francisco: Jossey-Bass.

Smith, Malcolm, and Richard Taffler. 1995. The incremental effect of narrative accounting information in corporate annual reports. Journal of Business Finance and Accounting 22: 1195-210. [CrossRef]

Tan, Hun-Tong, Elaine Ying Wang, and Bo Zhou. 2014. When the use of positive language backfires: The joint effect of tone, readability, and investor sophistication on earnings judgments. Journal of Accounting Research 52: 273-302. [CrossRef]

Tan, Hun-Tong, Elaine Ying Wang, and Bo Zhou. 2015. How does readability influence investors' judgments? Consistency of benchmark performance matters. The Accounting Review 90: 371-93. [CrossRef] 
Taylor, Eileen, and Jennifer Riley. 2017. Leveling the playing field for less-sophisticated non-professional investors: Does plain English matter? Journal of Capital Markets Studies 1: 36-57. [CrossRef]

Yayla, Ali Alper, and Qing Hu. 2011. The impact of information security events on the stock value of firms: The effect of contingency factors. Journal of Information Technology 26: 60-77. [CrossRef] 